\title{
UMA PROPOSTA PARA O ENSINO DA ÉTICA NAS FACULDADES DE MEDICINA
}

\author{
J. Rodrigues Coura( $\left.{ }^{*}\right)$
}

\section{RESUMO}

O ensino da ética, quando se faz nas escolas médicas brasileiras, é em geral feito de forma superficial e deslocado da prática nas Disciplinas de Medicina Legal e Deontologia.

Sugere-se no presente trabalho uma adaptação curricular na qual o ensino da ética seja feito em duas fases: a primeira no ciclo pré-clínico, na disciplina de Farmacologia, e a segunda no ciclo clinico, em disciplina de Introdução à Medicina, com um conteúdo de propedêutica e outra de ética médica.

Em etapas posteriores, o ensino da ética médica deveria ser feito através de seminários nos Departamentos de Clínica Médica, Cirurgia, Medicina Preventiva, Obstetrícia e Ginecologia, Pediatria, Psiquiatria e Medicina Legal. No internato e residência, esse ensino deveria ser predominantemente exemplare doutrinário, de acordo com os casos clínicos estudados, enquanto na pós-graduação ele deveria ser vinculado à disciplina de Metodologia Científica, com um forte conteúdo ético, moral e filosófico.

A preocupação com o ensino dos procedimentos éticos na prática médica nasceu com a própria criação do ensino médico pela Escola de Cós, cuja expressão mais pura e estilizada encontra-se no "juramento hipocrático", compromisso público e formal dos médicos ao graduarem-se, baseado nos preceitos do Pai da Medicina. O "primo non nocere" foi ouvido por nós inúmeras vezes ao longo do curso médico como transmissão informal e exemplar de mestre a discípulo, entretanto, o conceito de normas e procedimentos éticos para experimentação em seres humanos é relativamente recente.

Nos últimos anos a partir do julgamento de Nuremberg, após a segunda guerra mundial, quando uma série de atrocidades praticadas em prisioneiros por médicos nazistas sob o pretexto de experimentação médica vieram a público, algumas declaraçōes e normas internacionais foram editadas, entre as quais destacam-se o chamado Código de Nuremberg em 1947, a Declaração de Helsinki (Helsinki I) na 18. ${ }^{a}$ Assembléia Médica Mundial em 1964, revista pela 29. a Assembléia Médica Mundial realizada em Tóquio, em 1975 (Helsinki II) e diversas outras manifestações expressas em publicação do Conselho para Organizaçōes Internacionais de Ciências Médicas (CIOMS), nos anais de sua 14. ${ }^{\text {a }}$ Conferência Internacional realizada na cidade do México, de 1 a 3 de dezembro de $1980^{(3)}$. Mais recentemente (1982), a Organização Mundial de Saúde e o CIOMS publicaram uma proposta internacional de "guidelines" para pesquisa biomédica envolvendo seres humanos ${ }^{(2)}$ como conseqüência de uma série de estudos que vêm realizando desde 1976 sobre o assunto.

O ensino curricular da ética sempre foi colocado em posição secundária em relação às chamadas áreas de concentração em nossas Faculdades de Medicina. Embora 37 das 75 Escolas Médicas do nosso País incluam em seus currículos o ensino do que chamam

(*)Professor Titular do Departamento de Medicina Preventiva da Faculdade de Medicina da UFRJ. Diretor do Instituto Oswaldo Cruz e Vice-Presidente de Pesquisas da Fundação Oswaldo Cruz. 
ética médica, segundo afirma Belchior em trabalho recente(1), o que ocorre na realidade é que a maioria delas confundem o ensino da ética com a inclusão de alguns temas de Deontologia Médica como complemento da Disciplina de Medicina Legal. Como exemplo, cito uma das mais tradicionais Faculdades de Medicina do nosso País que em seu programa de "Medicina Legal e Deontologia", com uma carga horária total de 60 horas, reserva 9 Unidades de sua temática para a Medicina Legal e a $10 .^{a}$ e última para o que chama de "Deontologia", creio que dedicando menos de 6 horas para o seguinte temário:

\begin{abstract}
'Ética Médica. Condiçōes necessárias para o exercício legal da medicina. Curandeirismo e charlatanismo. Conselhos de Medicina. Relacionamento do médico com os pacientes. O dever de tratar. A dedicação, a afabilidade e a ação do confortante. A autoridade do médico em face do paciente em estado de iminente perigo de vida. Relacionamento do médico com os seus colegas. Os deveres de respeito e cortesia. A concorrência desleal e o desvio de clientela. A conferência médica. Organização da vida profissional. Responsabilidade médica. Honorários profissionais. Recursos de defesa do médico".
\end{abstract}

As discussōes sobre o ensino da ética médica nas Faculdades de Medicina e Centros de Ciência da Saúde estão em plena evolução em todo o mundo. Alguns, como Rivero Serrano(4), da Academia Nacional de Medicina do México, afirmam que o ensino da ética médica tanto para os estudantes de graduação como para os residentes e médicos em exercício, não deve consistir da análise de conceitos teóricos e sim do próprio exercício da atividade, e finaliza: "a ética médica se ensina exercitando-a". Outros advogam o ensino da ética por teólogos, filósofos ou "eticistas", com maior ênfase ora no ensino do humanismo médico, ora nas ciências da conduta. Finalmente os de visão mais eclética, acreditam que a cooperação entre "eticistas" ou filósofos e professores-médicos dariam os melhores resultados.

Uma interessante experiência vem sendo realizada na Universidade de Chicago sobre o ensino da ética médica para estudantes de graduação(5). Um programa de um mês, com sessôes de uma hora a uma hora e meia, 3 vezes por semana, é desenvolvido por estudantes do $3 .^{\circ}$ ano médico, que pas- sam em grupos pela Unidade de Cuidados Intensivos do Hospital, onde selecionam os casos para apresentação e discussão na sala de conferência. A discussão é coordenada por um membro do "staff' médico e os casos são apresentados pelos estudantes de medicina, porém com participação multidisciplinar de profissionais e estudantes de enfermagem, serviço social, direito e ocasionalmente teologia e filosofia. O programa tem se mostrado muito estimulante e bem sucedido.

Apesar de uma série de opiniōes e experiências recentes, ainda estamos muito longe de um consenso sobre a melhor metodologia de ensino da ética médica. Perguntas básicas como: quem, como, quando e onde ensinar a ética médica ainda não foram definitivamente respondidas. Entretanto, para efeito de discussão ousaria dar algumas respostas e sugestões, sem a menor pretensão de tê-las como definitivas ou acertadas.

a) O ensino da ética médica deveria ser feito predominantemente de forma doutrinária e exemplar por professores-médicos entre os mais experientes, principalmente aqueles com o carisma de Chefe de Escola.

b) Além do ensino doutrinário e exemplar contínuo, na forma do item anterior, o ensino da ética deveria ser feito em etapas sucessivas: a primeira no ensino pré-clínico, possivelmente na Disciplina de Farmacologia, onde as bases da experimentação em "anima villi" e em "anima nobili" são iniciadas; a segunda concentrada em uma disciplina de Introdução à Medicina, com um conteúdo de propedêutica e outro de ética médica no início do $3 .^{\circ}$ ano, correspondente ao $5 .^{\circ}$ período, com a participação direta do aluno e, em etapas posteriores, através de seminários nos Departamentos de Clínica Médica, Medicina Preventiva, Cirurgia, Obstetrícia e Ginecologia, Pediatria, Psiquiatria e Medicina Legal.

c) O ensino da ética médica no Internato e na Residência deveria ser predominante, exemplar e doutrinário, de acordo com os casos estudados e eventualmente através 
de seminários multidisciplinares e multiprofissionais, enquanto que na Pós-graduação este ensino deveria estar vinculado à Disciplina de Metodologia Científica, com um forte conteúdo ético, moral e filosófico.

Não creio que sejam necessárias grandes modificações curriculares para a adoção das sugestōes apresentadas, uma vez que as Disciplinas e Departamentos mencionados já existem na quase totalidade das Escolas Médicas Brasileiras e ministram normalmente o seu conteúdo didático próprio, necessitando apenas de uma pequena adaptação para a necessária ênfase ao conteúdo ético, que sabem necessário e indispensável à formação de um bom profissional da saúde. Resta, entretanto, um grande esforço para uma mudança de atitude, componente essencial e-integrante da própria ética, que tem como cenário as instituições e a sociedade e como atores, os professores e alunos.

Sumariamente, creio que as seguintes adaptaçōes curriculares seriam necessárias não somente para atender aos objetivos éticos da experimentação em seres humanos, mas também, principalmente, para o estímulo ao desenvolvimento da ética médica como um todo em nossas instituições de ensino médico:

1) Adaptação de um conteúdo didático sobre "Bases Éticas da Experimentação", tanto em animais como em seres humanos, para estudantes do curso préclínico, possivelmente tomando como modelo e campo de ação a Disciplina Farmacologia, por sua maior facilidade em desenvolver um programa dessa natureza.

2) Criação ou adaptação no primeiro período do ciclo clínico de uma Disciplina de "Introdução à Medicina" com dois conteúdos didáticos bem definidos: a) Propedêutica Médica e b) Ética Médica, onde os alunos ao lado do treinamento do diagnóstico clínico, tomassem conhecimento dos documentos legais vigentes, das normas éticas internacionais, em revisão do que fora visto no curso pré-clínico e da metodologia da experimentação clínica, inclusive limitações e críticas aos métodos invasivos de diagnóstico e investigação e a análise da introgênese física, mental e social, trazendo tanto quanto possível para a discussão os exemplos vividos no próprio ambiente hospitalar.

3) Desenvolvimento de seminários específicos sobre procedimentos éticos nas áreas de Clínica Médica, Medicina Preventiva, Cirurgia, Obstetrícia e Ginecologia, Pediatria, Psiquiatria e Medicina Legal, com a máxima participação do aluno na análise e discussão de problemas concretos.

4) Recomenda-se uma cuidadosa revisão dos programas de "Metodologia Científica" dos Cursos de Pós-graduação, para que neles se insiram um forte conteúdo ético, moral e filosófico sobre a investigação "in anima nobili".

Finalmente, mas não por último, deve ser lembrado que todo esse programa não passará de meras intençōes se o comportamento exemplar das instituiçōes de ensino, dos seus mestres e diretores não se coadunar com os programas e doutrinas deles emanados.

\section{ABSTRACT}

Formal teaching of ethics in Brazilian Medical Schools is generally superficial, and is executed beyond medical practice, in the discipline of Legal Medicine.

This paper suggests a curriculum adaptation in Medical Schools is the sense of teaching ethics in two phases: the first, pre-clinic, in the discipline of Pharmacology, and the second in the clinical practice as an introduction to medical work.

Teaching of ethics during the medical course should be carried out in the form of seminaries in the departments of Internal Medicine, Surgery, Preventive Medicine, Obstetrics and Gynaecology, Psychiatry and Legal Medicine. During medical residency ethics should be taught according to observed clinical cases while during post-graduation ethics should be included as an important moral and philosophical component in the discipline of Scientific Methodology. 


\section{REFERÊNCIAS BIBLIOGRÁFICAS}

1. BELCHIOR, M. - The teaching of Medical Ethics in Brazil. In Proceedings of the XIVth CIOMS Round Table Conference, Geneva, 1981.

2. BIOMEDICAL RESEARCH INVOLING HUMAN SUBJECTS. Proposed International Guidelines. A joint project of the WHO and the CIOMS, Geneva, 1982.

3. MEDICAL ETHICS AND MEDICAL EDUCATION.
Proceedings of the XIVth CIOMS Round Table Conference, Geneva, 1981.

4. SERRANO, O. R. - La enseñanza de la Etica Medica en las Escuelas de Medicina. In Proceedings of the XIVth CIOMS Round Table Conference, Geneva, 1981.

5. SIEGLER, M. - Medical Ethics Instruction for Medical Students in the Clinical Years. In Proceedings of the XIVth CIOMS Round Table Conference, Geneva, 1981. 